\title{
A new scheme based on correlation technique for generator stator fault detection-part $\pi$
}

\author{
R. Abd Allah', S. M. Mohamed ${ }^{2}$, E. H. Shehab-Eldin' ${ }^{2}$, M. E. Masoud ${ }^{2}$ \\ ${ }^{1}$ Buraydah Colleges, Faculty of Engineering, Electrical Power Department, Qassim Region, Kingdom of Saudi Arabia \\ ${ }^{2}$ Helwan University, Faculty of engineering, Department of Electrical Machines\& Power Engineering, Cairo, Egypt
}

\section{Email address:}

Mohandes_Ragab@yahoo.com (R. Abd Allah), powervisionegypt@gmail.com (S. M. Mohamed), shehab_eldin01@yahoo.com (E.H. Shehab-Eldin)

\section{To cite this article:}

R. Abd Allah, S. M. Mohamed, E. H. Shehab-Eldin, M. E. Masoud. A New Scheme Based on Correlation Technique for Generator Stator Fault Detection-Part $\pi$. International Journal of Energy and Power Engineering. Vol. 3, No. 3, 2014, pp. 147-153.

doi: $10.11648 /$ j.ijepe. 20140303.16

\begin{abstract}
An experimental model for the synchronous generator was implemented and windings tapped at different positions to obtain faults at different locations on the stator windings. LABVIEW was used to obtain an interface between the experimental model and the suggested digital relay; whereas the proposed algorithm is executed using MATLAB. The obtained experimental results showed a great similarity with those obtained from ATP-EMTP simulation and that indicated the capability of safe application of the new auto/cross correlation protection technique.
\end{abstract}

Keywords: Power System, Generator Protection, Fault Classification, Correlation Coefficient, Internal Faults, ATP-EMTP

\section{Introduction}

Faults associated with synchronous generators may be classified as either insulation failures or abnormal running conditions [1-2]. An insulation failure in the stator winding will result in an inter-turn fault, a phase fault or a ground fault, but most commonly the latter since most insulation failures eventually bring the winding into direct contact with the core. Differential relays, in particular the digital ones, are used to detect stator faults of generators [3-5].

The proposed technique of digital relay for synchronous generators protection using statistical auto/cross correlation coefficients [6] was described in part I of this paper. The technique evaluation using the simulation results show that, the proposed technique is able to provide correct response rapidly for a wide range of different fault conditions. In this paper, the experimental part is presented including the following items:

$>$ Building up the laboratory model for the proposed digital relay using data acquisition card and all accessories.

$>$ Preparing a synchronous generator with stator windings tapping to execute different types of internal and inter-turn faults.
$>$ Interface between the used generator and proposed digital relay.

Obtain test results for internal and external faults.

$>$ Verify the performance of proposed digital relay under various fault conditions.

\section{Laboratory Model Description}

The laboratory model consists of the following main parts:

(a) Synchronous generator under test.

(b) Three phase induction motor (as prime mover).

(c) Three phase load.

(d) Transducers (Current transformers).

(e) Data acquisition card.

(f) Digital relay (Computer, PC).

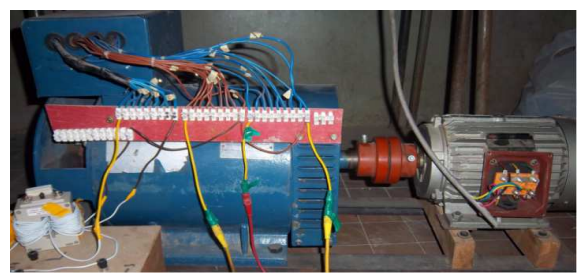

Figure 1. Laboratory Model Main Parts. 
The main parts of the laboratory model used in testing the proposed technique for synchronous generator protection are shown in Fig. 1. It consists of the synchronous generator, prime mover induction motor and the used load; their data are listed in Appendix A.

\subsection{Synchronous Generator Winding Taps}

The synchronous generator under test is the source of AC power and electrical energy for loads. The stator windings of the synchronous generator are modified by the authors in order to obtain different taps to facilitate examining internal and inter-turn faults at different positions. Table 1 shows the obtained winding taps and the associated voltage. This will enable us to examine various types of internal and inter-turn faults along the stator windings. Fig. 2 shows the stator winding taps of synchronous generator under test.

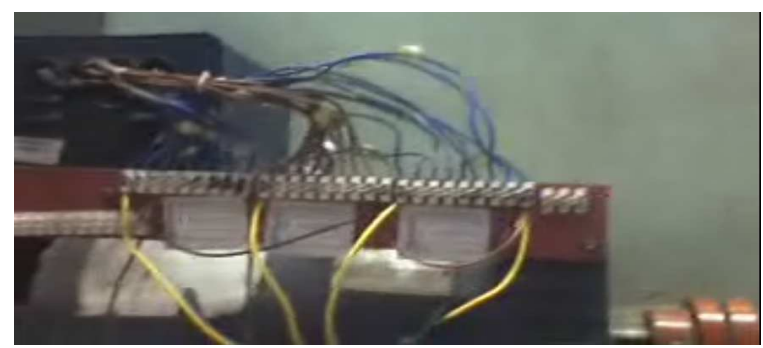

Figure 2. Stator Winding Taps of Synchronous Generator under Test.

Table 1. Stator winding taps and the associated voltage.

\begin{tabular}{cccc}
\hline $\begin{array}{c}\text { Terminal } \\
\text { block number }\end{array}$ & $\begin{array}{c}\text { Number of } \\
\text { turns }\end{array}$ & $\begin{array}{c}\text { \% Winding for } \\
\text { each phase }\end{array}$ & $\begin{array}{c}\text { Phase voltage } \\
\text { (A-N) (Volt) }\end{array}$ \\
\hline 1 & 168 & 100 & 220 \\
2 & 84 & 50 & 110 \\
3 & 72 & 42.86 & 94.28 \\
4 & 60 & 35.71 & 78.57 \\
5 & 48 & 28.57 & 62.86 \\
6 & 36 & 21.42 & 47.14 \\
7 & 24 & 14.28 & 31.43 \\
8 & 12 & 7.14 & 15.71 \\
9 & 0 & 0 & 0 \\
\hline
\end{tabular}

\subsection{Three Phase Induction Motor (As a Prime Mover)}

The three phase induction motor is functioning as a prime mover for providing the mechanical energy to synchronous generator. The induction motor data is listed in Appendix A.

\subsection{Three Phase Load}

The generator load is three phase variable resistances and inductive; their data are given in Appendix A.

\subsection{Current Transformer}

Two side currents of stator winding for synchronous generator are used as the input signals to the proposed differential relay; these currents are obtained through two current transducers per each phase. The current transducer convert the current signal to low voltage signal suitable for the input channel of the data acquisition card which operates with input voltage signals within $\pm 10 \mathrm{~V}$. the transformation ratio of the current transducer is $1 \mathrm{~A} / 100$ $\mathrm{mV}$ where the CT burden is $0.1 \mathrm{Ohm}$. The data of used current transformers are given in Appendix A.

\subsection{Data Acquisition Card (Ni Usb-6008/6009 Device)}

The data acquisition card (DAC) is used to convert the analog data into a suitable that can be used via a digital processor. The National Instruments USB-6008/6009 is data acquisition device; it provides connection to eight analog input (AI) channels, two analog output (AO) channels, 12 digital input/output (DIO) channels, and a 32bit counter with a Full-Speed USB interface. The Data acquisition card is characterized by 14-bit input resolution, 8 input channels single ended or 4 input channels differential and the sampling rate is $48 \mathrm{kHz}$. The DAC is adjusted to operate in differential mode. Two input channels for two side's currents per phase are used with a sampling frequency of $1 \mathrm{kHz}$ for each channel.

\subsection{Digital Relay}

PC computer is used to virtually simulate the intelligent electronic device (IED) relay. The computer in this case is functioning as digital relay. The specification of this computer is HP Pavilion Entertainment PC, processor: 2.1 GHZ and installed memory (RAM): 3.00 GB.

Figure 3 shows wiring from CTs burden of phase " $A$ " to two input channels of NI USB-6008/6009 device to operate in differential mode.

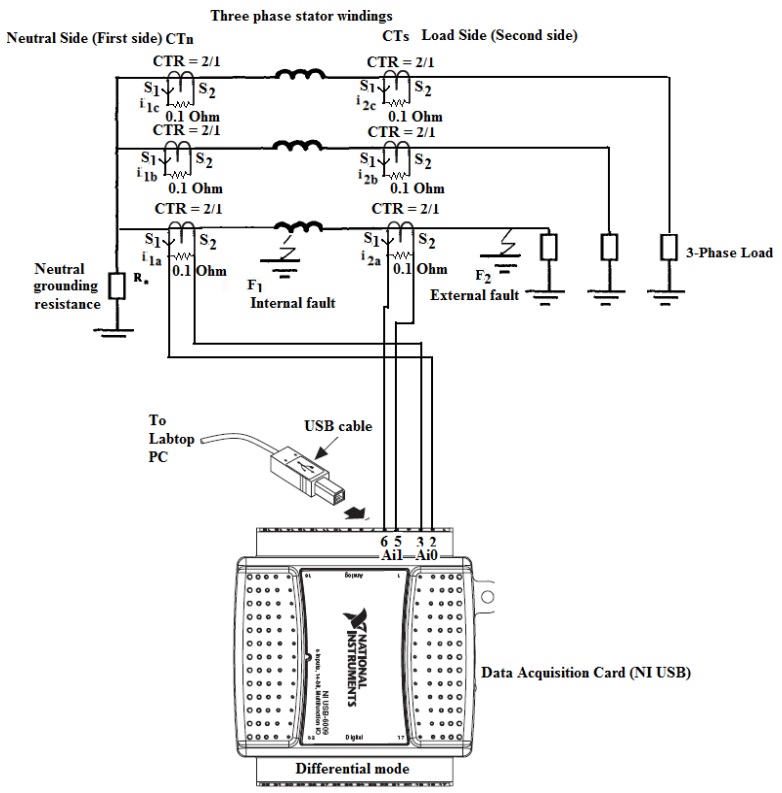

Figure 3. Laboratory Model Main Parts of the Protection System.

\section{Basic Principle}

It is worth to mention that the experimental results described in this part depends on the protection algorithm 
developed and theoretically examined in part I of this paper. For convenience the suggested protection algorithm is based on auto/cross-correlation theory. The technique measures the currents at the both ends of stator windings and uses the calculated auto/cross-correlation coefficients for the two-side currents of each phase, for making relay trip or no trip decision. The suggested protection algorithm can give good results without filter because it uses a number of samples per each correlated window. The proposed algorithm used a correlated window of one cycle in these tests.

Tripping action of the algorithm relies on the conditions given in Table 2 .

Table 2. Auto/cross-correlation coefficient ranges at different fault conditions.

\begin{tabular}{|c|c|c|c|}
\hline $\begin{array}{c}\text { Generator } \\
\text { condition }\end{array}$ & $\begin{array}{c}\text { Cross-correlation (Between the two currents of } \\
\text { neutral and load sides) }\end{array}$ & $\begin{array}{l}\text { Auto-correlation (of current at neutral side or } \\
\text { of current at load side) }\end{array}$ & Relay action \\
\hline 1. Normal operation & 1 for all 3-phase & 1 for all 3-phase & Blocking \\
\hline 2. external fault & 1 for all 3-phase & $<1$ at least one phase & Blocking \\
\hline 3. internal fault & $<1$ at least one phase & $<1$ at least one phase & Tripping \\
\hline
\end{tabular}

Testing the performance of the proposed algorithm for phase ' $A$ ' stator winding protection, at different types of faults internally and externally, is described in the next section.

\section{Experimental Relay Performance}

Testing of the proposed technique based on the auto/cross-correlation coefficients for generator protection (see part I of this paper) was completed for various cases. All results shown in this section are done under the operating conditions listed in Table 3.

Table 3. Operating conditions for practical model.

\begin{tabular}{ll}
\hline Electrical component (operating condition) & Data \\
\hline $\begin{array}{l}\text { generator Load impedance } \\
\text { generator load current }\end{array}$ & $\begin{array}{l}220+\mathrm{j} 0.0 \mathrm{Ohm} \\
1 \mathrm{amp}\end{array}$ \\
Operating phase voltage (RMS) of generator & $220 \mathrm{Volt}$ \\
Generator grounding impedance & $0.0 \mathrm{ohm}$ \\
\hline
\end{tabular}

\subsection{Case 1: Normal Operation at Generator Load Current $=1 \mathrm{Amp}$}

As expected in normal operation condition, no trip signal is initiated due to cross-correlation between the two current signals of neutral and load sides, auto-correlation of current signal at neutral side and auto-correlation of current signal at load side are fixed and approximately one. This is illustrated in Figs. 4 (a-e).

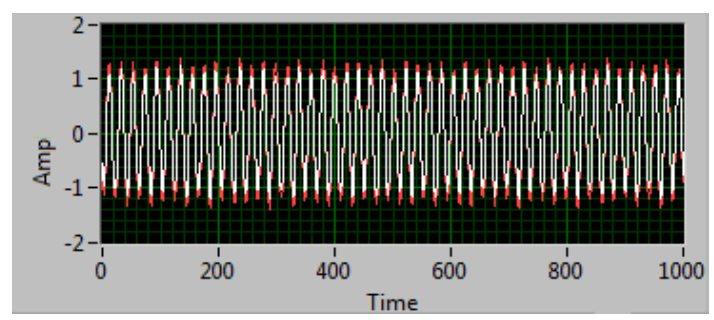

(a) Generator Neutral and Load Currents for Phase A.

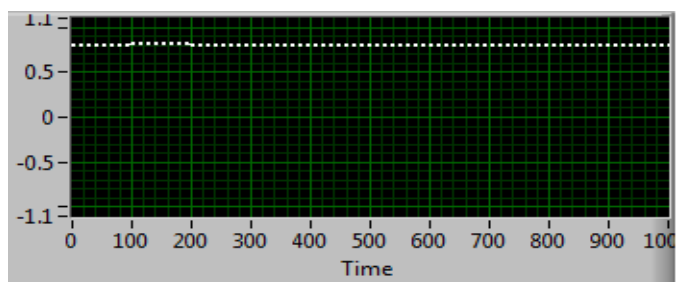

(b) Auto-correlation for Neutral Current.

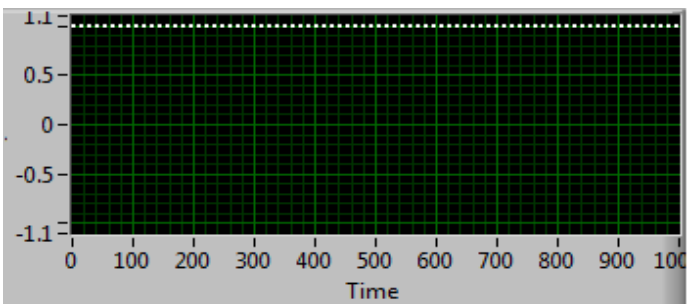

(c) Cross-correlation between Neutral

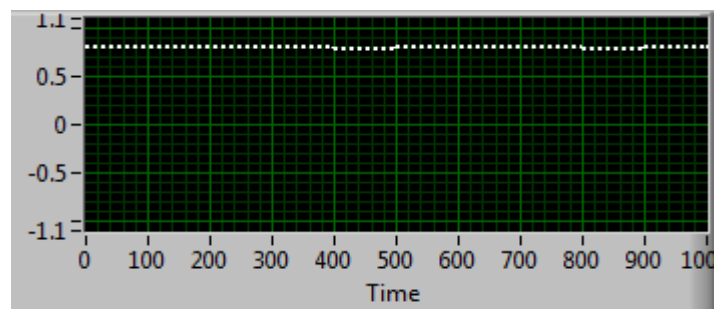

(d) Auto-correlation for Load Current.and Load Currents.

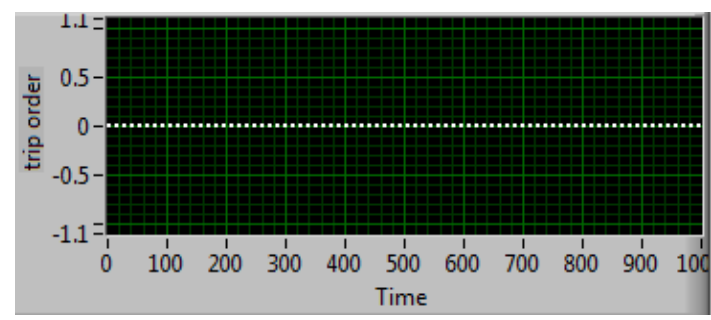

(e) No Trip Action for Case 1.

Figures 4 (a-e). Test Results for Case 1 (Normal Operation).

\subsection{Case 2: External SLG (C-N) Fault Through Resistance $\left(R_{f}\right)=10 \mathrm{Ohm}$}

Figures 5 (a-e) show the test results in case of external SLG $(\mathrm{C}-\mathrm{N})$ fault through resistance $\left(R_{f}\right)=10 \mathrm{ohm}$. The 
Figures present the phase " $A$ " generator current signals at the two neutral and load end sides, and their auto/crosscorrelation coefficients. In this case, it is noticed that the phase " $A$ '" primary currents for neutral and load sides during the fault are identical and higher than the pre-fault currents as shown in Fig. 5(a). The calculated crosscorrelation coefficients are equal and close to unity before and during fault occurrence as presented in Fig. 5(b). The algorithm calculates cross-correlation coefficient between each two corresponding windows (each window is one cycle) for two current signals at the neutral and load end sides. The calculated auto-correlation coefficients are fixed, equal and close to unity before fault occurrence, and they decrease with fault occurrence (see Figs. 5 (c-d)). The algorithm calculates auto-correlation coefficient between each two successive windows shifted from each other by one cycle (each window is one cycle) for current signals at the neutral and load end sides. Auto-correlation coefficients is estimated for differentiation between external fault and normal operation, their values are closely to unity for neutral and load current signals in case of normal operation and they are less than one in case of external faults as shown in this case.

A trip flag depends on the cross-correlation values, if their values are less than unity then a trip signal is sent for isolation generator $\mathrm{CB}$. But this case is external fault condition and no tripping signal is issued as shown in Fig. 5(e).

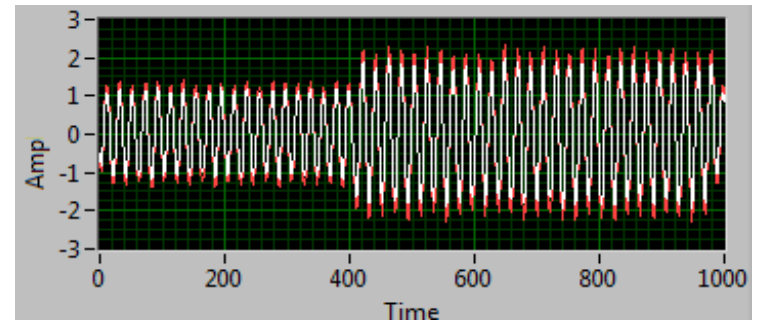

(a) Generator Neutral and Load Currents

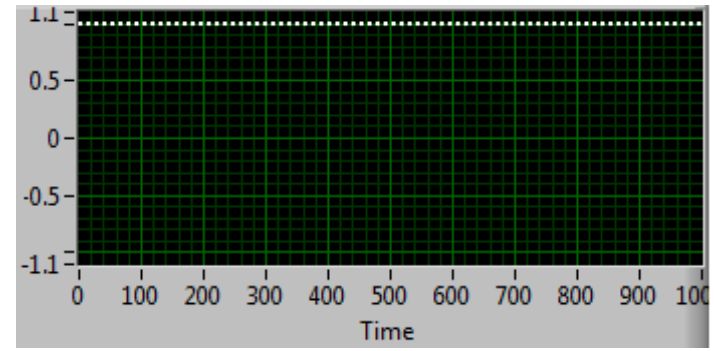

(b) Cross-correlation between Neutral

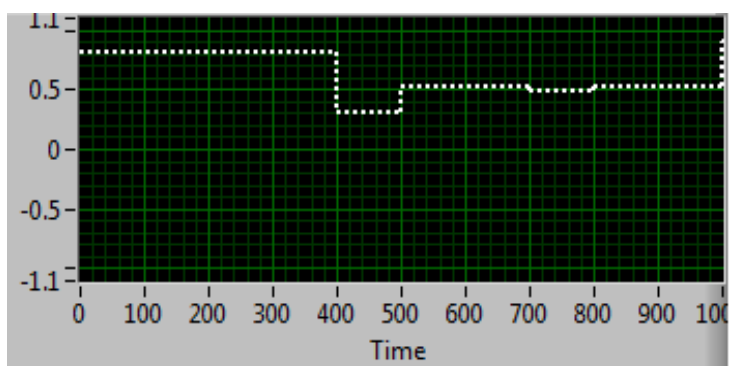

(c) Auto-correlation for Neutral Current for Phase A.

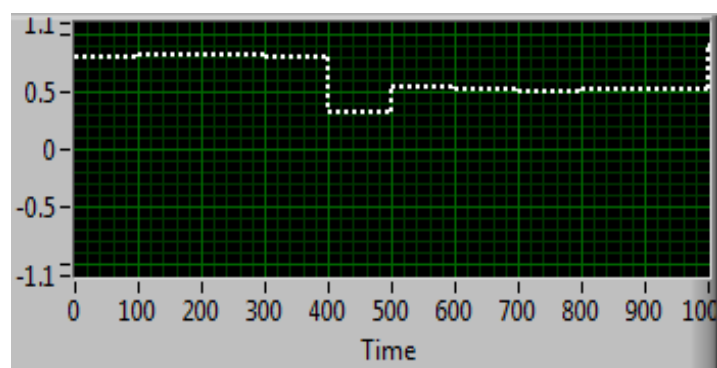

(d) Auto-correlation for Load Current. and Load Currents.

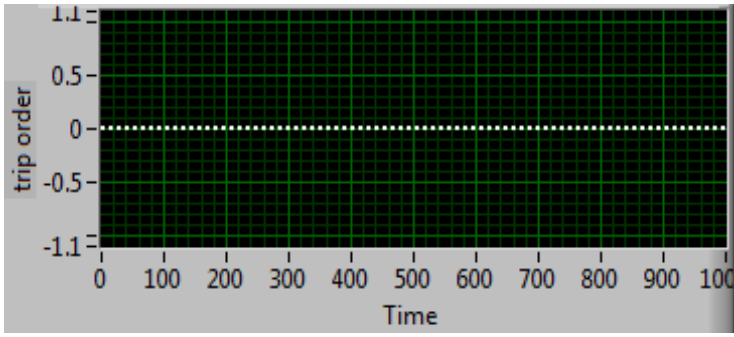

(e) No Trip Action for Case 2 .

Figures 5(a-e). Test Results for Case 2.

\subsection{Case 3: External DL (A-C) Fault Through Resistance $\left(R_{f}\right)=2.5 \mathrm{Ohm}$}

As expected in case of external DL (A-C) fault through resistance $\left(R_{f}\right)=2.5 \mathrm{ohm}$, no trip signal is initiated due to cross-correlation coefficient between the two current signal of neutral and load sides are fixed and approximately one. Auto-correlation coefficients of current signals at neutral side and at load side are less than one with fault occurrence. This is illustrated in the presented Figs. 6 (a-e).

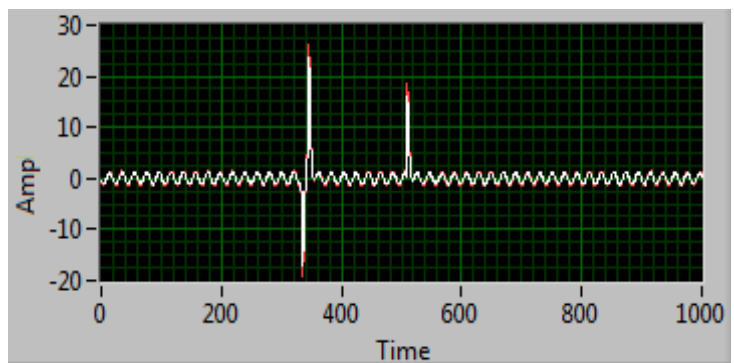

(a) Generator Neutral and Load Currents for Phase A.

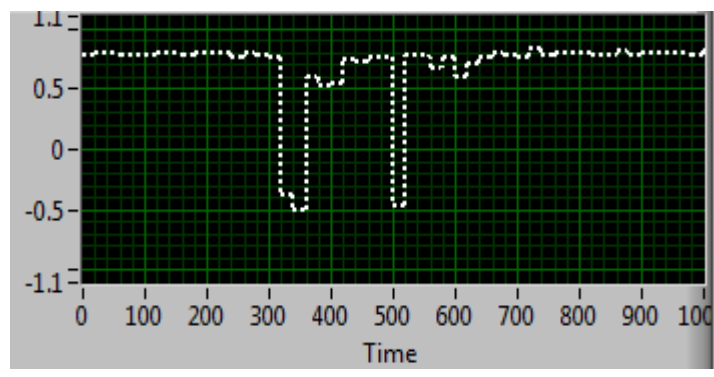

(b) Auto-correlation for Neutral Current. 


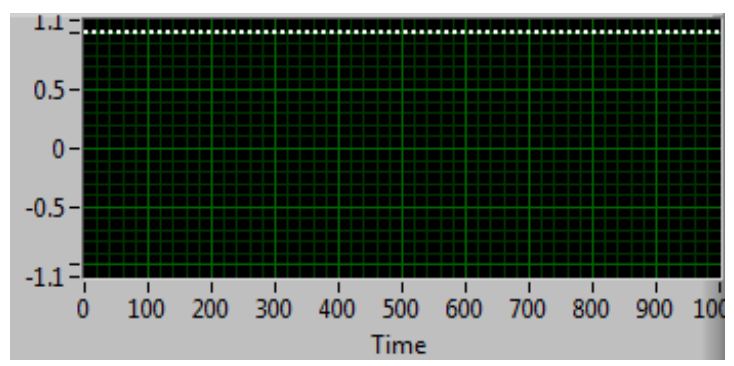

(c) Cross-correlation between Neutral

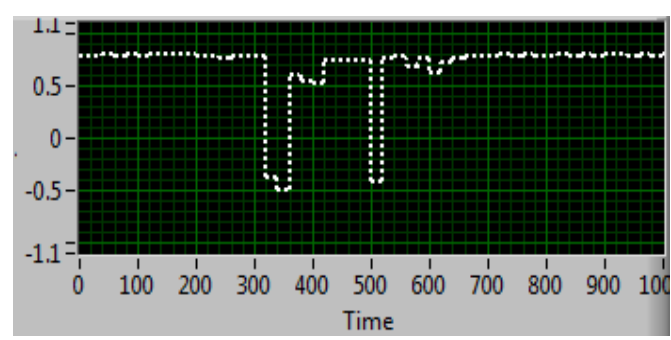

(d) Auto-correlation for Load Current. and Load Currents.

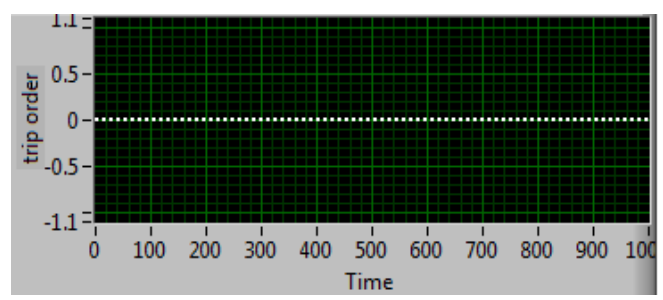

(e) No Trip Action for Case 3 .

Figures 6(a-e). Test Results for Case 3.

Many test results of internal fault conditions at various fault types and resistances are obtained, trip signal is initiated with fault start due to cross-correlation coefficient between the two current signals of neutral and load sides are less than one. Also, Auto-correlation coefficients of current signals at neutral side and at load side are less than one with fault occurrence. This is illustrated in the following different cases of internal faults conditions.

\subsection{Case 4: Internal SLG (A-N) Fault Through} Resistance $\left(R_{f}\right)=2.5 \mathrm{Ohm}$ at $100 \%$ on Stator Winding

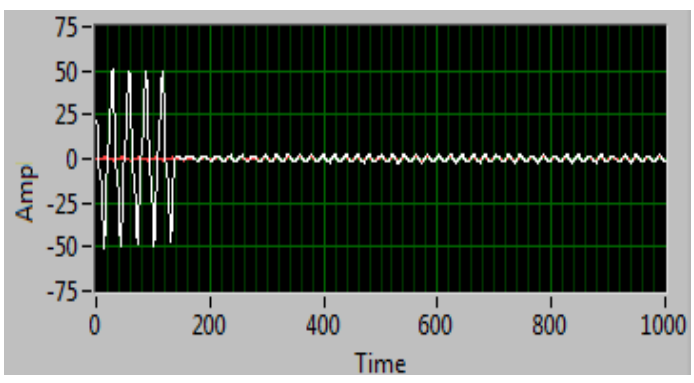

(a) Generator Neutral and Load Currents for Phase A.

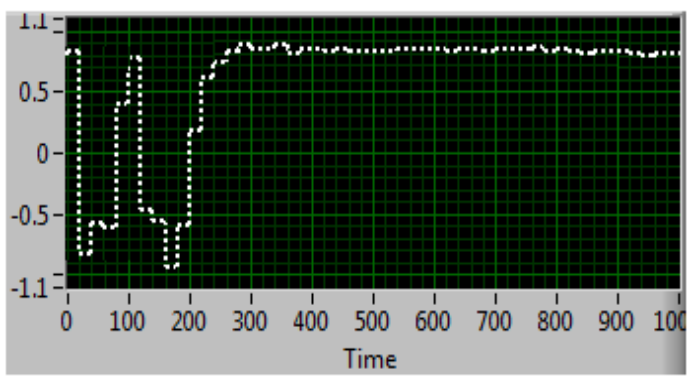

(b) Auto correlation for Neutral Current.

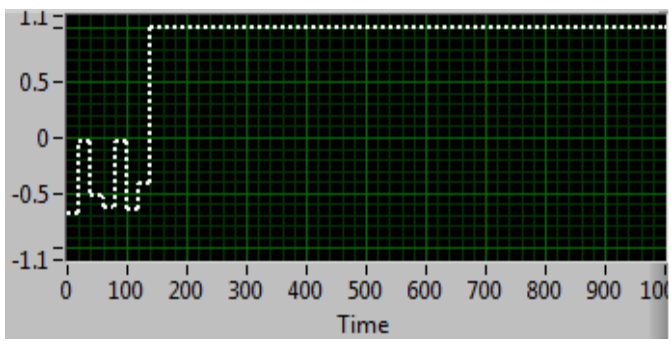

(c) Cross-correlation between Neutral

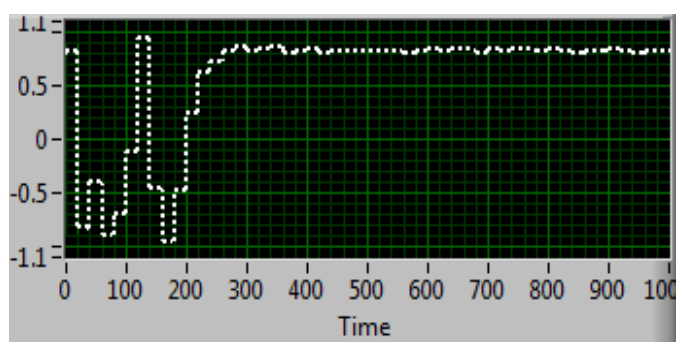

(d) Auto-correlation for Load Current. and Load Currents.

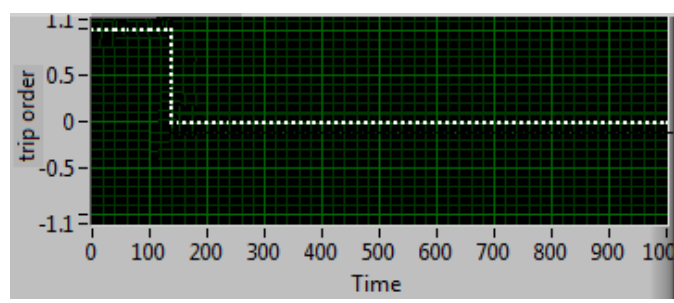

(e) Trip Action for Case 4

Figures 7(a-e). Test Results for Case 4.

4.5. Case 5: Internal DLG (A-B-N) Fault Through Resistance $\left(R_{f}\right)=2.5 \mathrm{Ohm}$ at $100 \%$ on Stator Winding

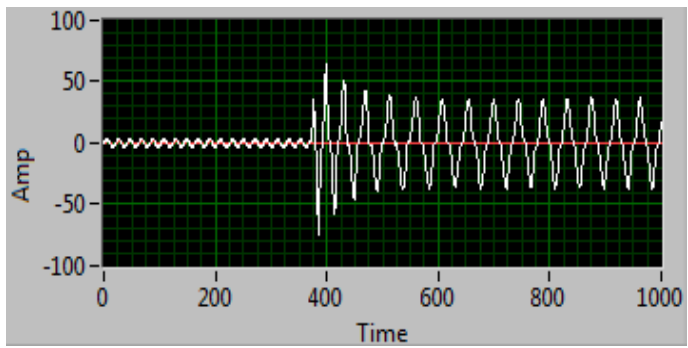

(a) Generator Neutral and Load Currents for Phase A. 


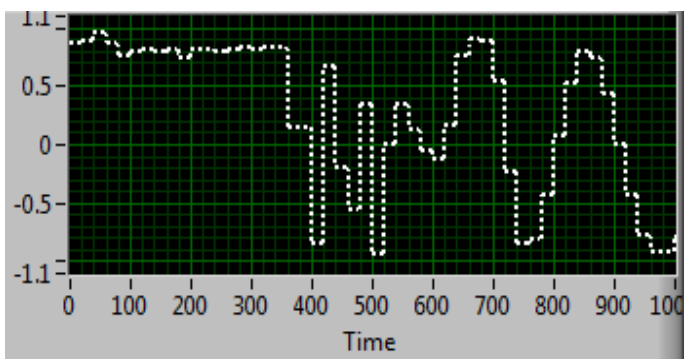

(b) Auto-correlation for Neutral Current.

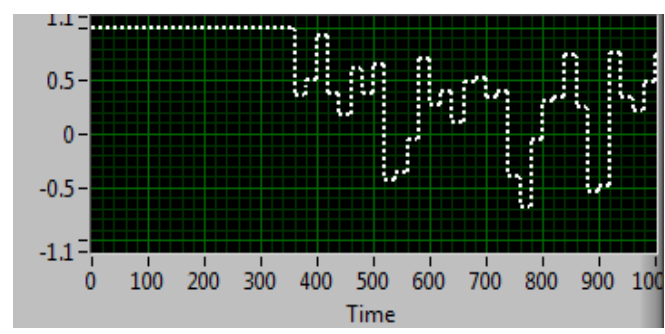

(c) Cross-correlation between Neutral

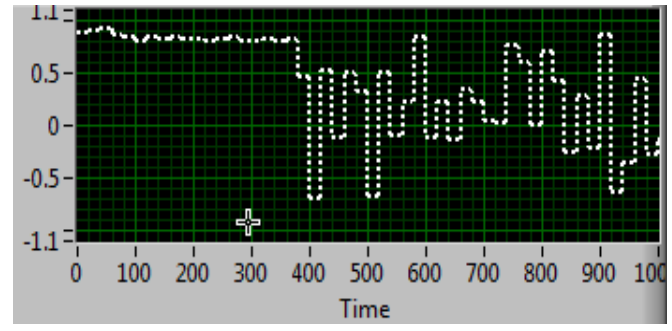

(d) Auto-correlation for Load Current. and Load Currents.

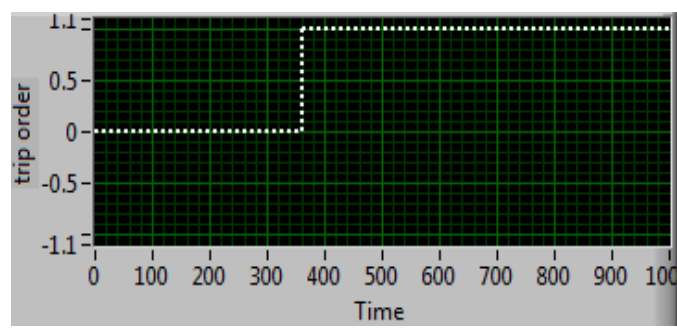

(e) Trip Action for Case 5 .

Figures 8(a-e). Test Results for Case 5.

4.6. Case 6: Inter-Turn Fault Through Resistance $\left(R_{f}\right)=$ 0 Ohm Between Taps7.14\%- 14.28\% On Stator

Winding

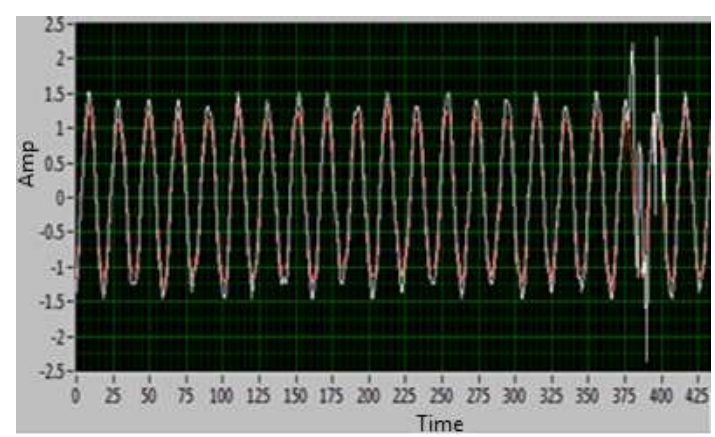

(a) Generator Neutral and Load Currents for Phase A.

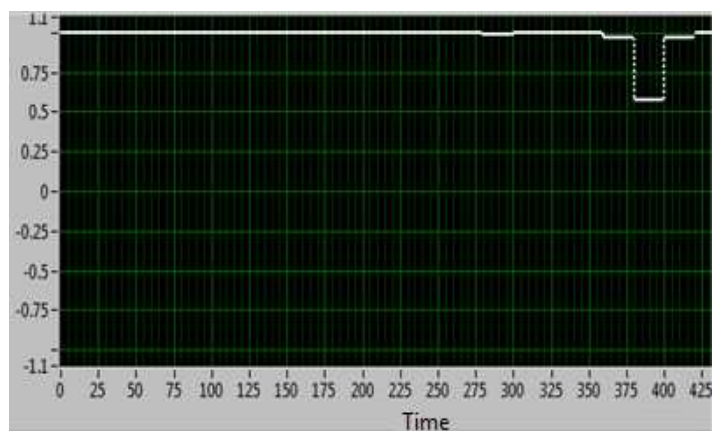

(b) Cross-correlation between Neutral and Load Currents.

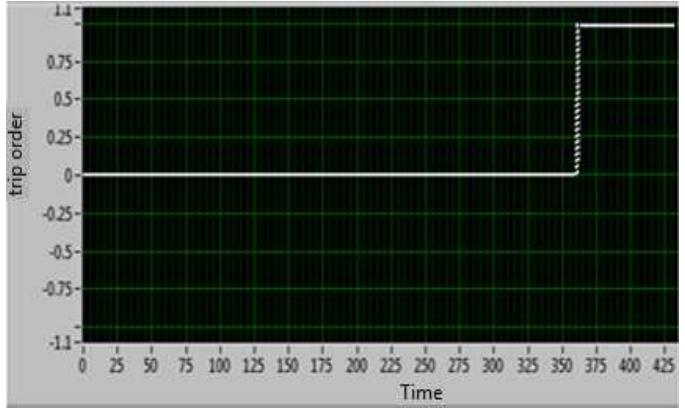

(c) Trip Action for Case 6

Figures 9(a-e). Test Results for Case 6.

From the obtained results, it is clear that the proposed technique for differential protection algorithm of phase " $A$ " succeeded in differentiating between external and internal faults occurring on the generator stator besides identifying faulted phase(s) and detecting inter-turn faults in the same phase of stator winding. Thus a reliable and efficient technique has been presented for detecting generator stator winding internal and external faults by using both auto-correlation and cross-correlation functions.

\section{Conclusion}

Performance of the proposed protection algorithm for protecting synchronous generators was investigated on a laboratory model of a synchronous generator. The laboratory model is able to emulate the behavior of the actual power plant in the laboratory environment. The suggested digital relay has been implemented on PC computer; data acquisition card is used to convert the analog signals generated from current transducers into digital data used via a digital processor. The proposed algorithm has been examined experimentally under different operating conditions for various types of internal and external faults. The relay algorithm detects and classifies all faults within one cycle of the fundamental frequency after fault inception. Practical results showed that the proposed algorithm can differentiate between internal and external faults and consequently take the accurate decision by producing trip signal in case of internal faults and blocking signal in case of external faults. 
Appendix A. Electrical data of the main parts for the laboratory model.

\begin{tabular}{|c|c|}
\hline Electrical parameter & Data \\
\hline \multicolumn{2}{|l|}{ Synchronous Generator: } \\
\hline Туре & $\begin{array}{l}\text { STC-5 (KAIJ IELI GROUP, } \\
\text { CHINA) star connected }\end{array}$ \\
\hline Rated active power & $5 \mathrm{kWatt}$ \\
\hline Nominal voltage & $380 \mathrm{~V}$ \\
\hline Rated current & $9.5 \mathrm{Amp}$ \\
\hline Frequency & $50 \mathrm{~Hz}$ \\
\hline Rated speed & $1500 \mathrm{r} / \mathrm{min}$ \\
\hline Power factor & $\operatorname{Cos}(\phi)=0.8$ \\
\hline Excitation voltage & 82 Volt \\
\hline Excitation current & 3.6 Amp \\
\hline Number of poles & 4 poles/phase. \\
\hline Number of turns per phase & 168 \\
\hline Number of slots per phase & 12 slot/phase \\
\hline Neutral grounding resistance $\left(\mathrm{R}_{\mathrm{n}}\right)$ & $0.0 \mathrm{ohm}$ \\
\hline \multicolumn{2}{|l|}{$\begin{array}{l}\text { Prime Mover (3-phase induction } \\
\text { motor): }\end{array}$} \\
\hline Type & Y100L2-4 (MADE IN CHINA) \\
\hline Rated active power & 3k Watt (4HP) \\
\hline Nominal voltage & $380 \mathrm{~V}$ \\
\hline Rated current & $6.8 \mathrm{Amp}$ \\
\hline Frequency & $50 \mathrm{~Hz}$ \\
\hline Rated speed & $1430 \mathrm{r} / \min (47.67 \mathrm{~Hz})$ \\
\hline \multirow{2}{*}{\multicolumn{2}{|c|}{$\begin{array}{l}\text { Generator Load: } \\
\text { (a) Restive Load }\end{array}$}} \\
\hline & \\
\hline Type & Three phase Variable resistances \\
\hline $\mathrm{R}_{\text {load }}$ & $220-29.33 \mathrm{ohm}$ \\
\hline $\mathrm{I}_{\mathrm{load}}$ & 1-7.5 Amp \\
\hline \multicolumn{2}{|l|}{ (b) Inductive Load } \\
\hline Type & Three phase Variable Inductances \\
\hline $\mathrm{X}_{\text {Load }}$ & $1-4 \mathrm{kVAR}$ \\
\hline \multicolumn{2}{|l|}{ Current Transformer (CT): } \\
\hline Type & MSQ-40 \\
\hline CTR & $2 / 1$ \\
\hline Rated burden & $5 \mathrm{VA}$ \\
\hline Class & 1 \\
\hline
\end{tabular}

\section{References}

[1] "Protective Relays Applications Guide," The English Electric Company Limited, Relay Division, Stafford, 1975.

[2] Mozina C. J., IEEE Tutorial on the Protection of Synchronous Generators, IEEE Tutorial Course, IEEE Power Engineering Society Special Publ., no. 95 TP102, 1995.

[3] Megahed A. I., Student Member, IEEE, and O. P. Malik, Fellow, IEEE, "An Artificial neural network based digital differential scheme for synchronous generator stator winding protection," IEEE Transactions on Power Delivery, vol 14, 1999.

[4] A. I. Taalab, H.A. Darwish and T. A. Kawady, "ANN-Based Novel Fault Detector For Generator Windings Protection," IEEE Transaction on Power Delivery, Vol. 14, No 3, pp. 824 $-830,1999$.

[5] N.W.Kinhekar, Sangeeta Daingade and Ajayshree Kinhekar, "Current Differential Protection of Alternator Stator Winding," Paper submitted to the International Conference on Power Systems Transients (IPST2009) in Kyoto, Japan, 2009.

[6] W. Hauschild, and W. Mosch, "Statistical Techniques for High Voltage Engineering", hand book, English edition published by peter pere grinus Ltd., London, United Kingdom, chapter 2, pp. 78-79, 1992. 